\title{
The Collapse of the Bering Strait Ice Dam and the Abrupt Temperature Rise in the Beginning of the Holocene
}

\author{
CATHRINE SANDAL* AND DORON NOF ${ }^{+}$ \\ Department of Oceanography, The Florida State University, Tallahassee, Florida
}

(Manuscript received 9 July 2007, in final form 16 November 2007)

\begin{abstract}
This paper focuses on the abrupt increase in the oceanic and atmospheric temperature in the Northern Hemisphere at the beginning of the Holocene, approximately $11000 \mathrm{yr}$ before the present. De Boer and Nof hypothesized that, at that time, the Bering Strait (BS) opened up abruptly because of the breakup of an ice dam (by rising sea levels). It is proposed further here that this sudden opening caused an abrupt increase in the mean temperature of the Northern Hemisphere. An analytical, coupled ocean-atmosphere model is applied to the North Atlantic in an attempt to quantify the temperature change resulting from the opening of the BS. Heat, salt, and mass are all conserved within a box in the North Atlantic. A convection condition allows water to enter the deep layer and the island rule relates the wind field to the mass fluxes.

The conventional approach that the meridional overturning cell (MOC) was not operating during the Younger Dryas because of an overwhelming freshwater flux is adopted here. Opening the BS in the early Holocene allowed these freshwater anomalies to be flushed out into the Pacific, reviving convection and the transport of heat northward. Restarting convection with an open BS increases mean oceanic and atmospheric temperature by $3^{\circ}$ and $23^{\circ} \mathrm{C}$, respectively. These values are comparable to those found in both the Centre Européen de Recherche et d'Enseignement des Géosciences de l'Environnement (CEREGE) alkenone and Greenland Ice Sheet Project 2 (GISP 2) ice core records. Of course, restarting convection increases the temperature even with a closed BS, but in the closed BS case the oceanic increase is slightly higher $\left(4^{\circ} \mathrm{C}\right.$ instead of $\left.3^{\circ} \mathrm{C}\right)$, whereas the atmospheric is much lower $\left(17.5^{\circ} \mathrm{C}\right.$ instead of $\left.23^{\circ} \mathrm{C}\right)$. This is because, by requiring a continuous sea level around the Americas, an open BS allows the wind field to limit the amount of Southern Ocean water that enters the South Atlantic. This controlled volume flux ( $8 \mathrm{~Sv})$ is considerably smaller than that allowed into the Atlantic in the no-wind control closed BS case (17 Sv).
\end{abstract}

\section{Introduction}

At the beginning of the Holocene, approximately $11000 \mathrm{yr}$ before present (YBP), two major events occurred simultaneously in the Northern Hemisphere. First, the Bering Strait (BS) opened once more for throughflow of water because of rising sea levels, and second, the mean oceanic and atmospheric temperature around the North Atlantic (NA) abruptly increased (Fig. 1). We will consider the abrupt increase in mean

\footnotetext{
* Current affiliation: Bjerknes Center for Climate Research, Bergen, Norway.

+ Additional affiliation: Geophysical Fluid Dynamics Institute, The Florida State University, Tallahassee, Florida.

Corresponding author address: Doron Nof, 419 OSB, Dept. of Oceanography, The Florida State University, Tallahassee, FL 32306.

E-mail: nof@ocean.fsu.edu

DOI: $10.1175 / 2008 J P O 3877.1$
}

temperatures; the abruptness will be attributed to the release of a temporary iceberg jam, which initially blocked the BS. The associated temperature changes are the focus of this study.

The jamming idea was first put tentatively forward by de Boer and Nof (2004a,b hereafter DN04) and was then put on firmer ground with the aid of recent laboratory experiments that addressed the various issues associated with the related sea level rise (Sandal and Nof 2008b). Regardless of how fast it opens up, opening the BS imposes two separate and independent processes. First, DN04 showed that it allows a quick (200 yr or less) flushing of any salinity anomaly (which capped the convection in the Atlantic during the Younger Dryas) out of the Atlantic and into the Pacific, thereby reviving the convection. Second, we shall show here that it allows the global wind field to control the amount of water entering the Atlantic both from the Southern Ocean (SO) and the Arctic Ocean because an 


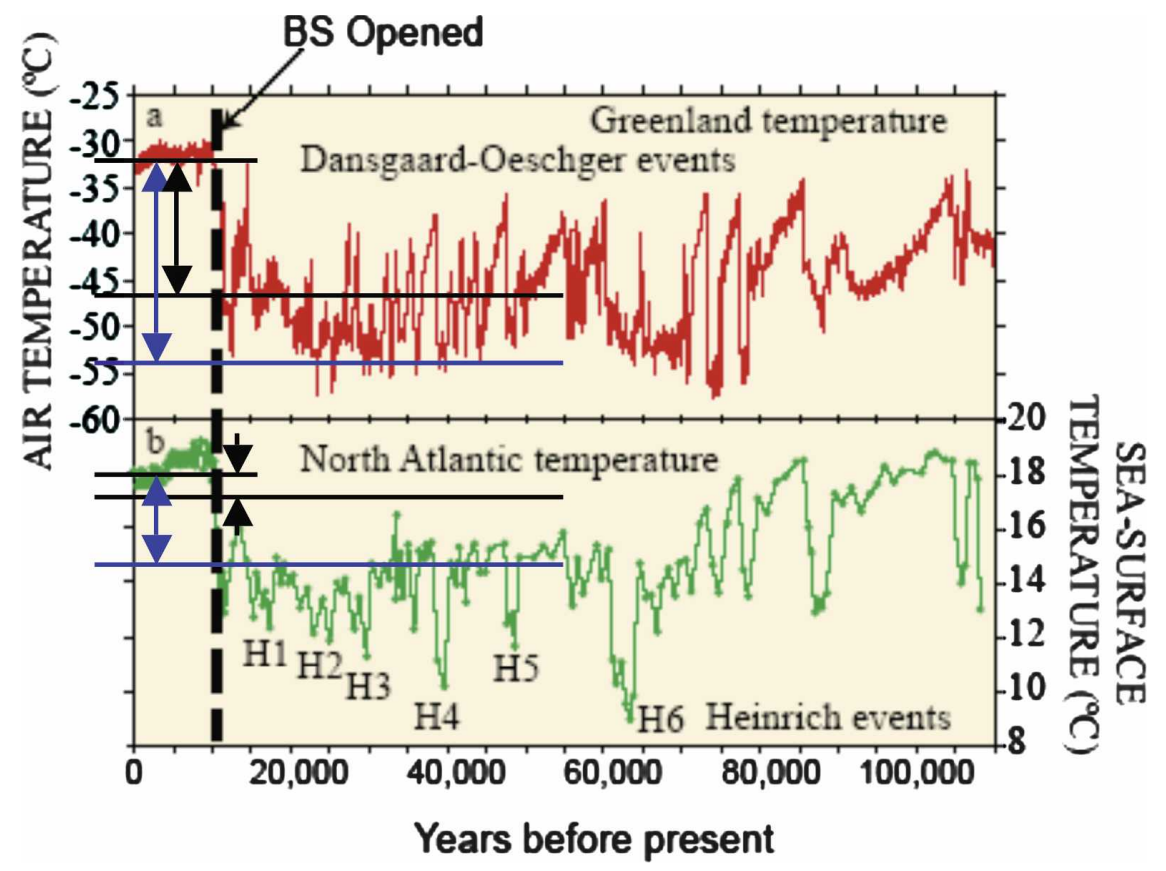

FIG. 1. Air and oceanic temperatures taken from the oxygen isotope record from the Greenland GISP 2 ice core and CEREGE alkenone record (Bard 2002) with our superimposed calculations (horizontal lines). At the opening of the BS, the mean temperature of both ocean and atmosphere increased dramatically and abruptly. Our model predictions are shown with horizontal blue and black lines. Blue arrows indicate the temperature change found between a convecting open BS (Holocene) and a nonconvecting closed BS (Younger Dryas). Black arrows indicate the mean temperature change (found using our coupled analytical model) between a convecting open BS and a mean of the intermittent convecting/ nonconvecting closed BS.

open BS forces the sea level to be continuous around the Americas. (Mathematically, this comes about through the island rule.)

\section{a. Background}

It is often suggested that reorganizations of the overturning circulation caused abrupt climate changes during the last glacial period (Bond et al. 1993; Broecker 1994; Blunier et al. 1998; Cacho et al. 1999; Bard et al. 2000; Boyle 2000; Labeyrie 2000; Marotzke 2000; Clark et al. 2002; Sandal and Nof 2008a, hereafter SN08). DN04 examined the distinct reduction in temperature fluctuations (not mean changes) around Greenland at the beginning of the Holocene using both analytical and numerical models. They linked this reduction of in situ temperature fluctuations to the stabilization of convection in the North Atlantic through the opening of the Bering Strait. They proposed that the BS acts dynamically as a switch between stable and unstable climate regimes, where a stable regime consists of an open BS and an unstable one of a closed BS. This is further supported by Hu and Meehl's (2005) numerical simu- lations, in which the flow through the BS decreased and even reversed when the North Atlantic was flushed with sufficient freshwater to weaken the meridional overturning cell (MOC) significantly.

Between the last deglaciation and modern times, sea level rose by about $120 \mathrm{~m}$ (see, e.g., Alley et al. 2005; Yokoyama et al. 2000). The BS opened for throughflow about 11000 YBP (see, e.g., Sandal and Nof 2008b; Dyke et al. 1996), which coincides with the abrupt increase in mean oceanic and atmospheric temperature found in both the Centre Européen de Recherche et d'Enseignement des Géosciences de l'Environnement (CEREGE) alkenone and the Greenland Ice Sheet Project 2 (GISP 2) ice core records (Fig. 1). In contrast to the DN04 stability analysis, which attributes the variations of the stability properties of the system to the opening of the BS, we shall focus here on the question of whether the abrupt mean increase in temperature is also due to the opening of the BS. We shall argue that the answer to that question is yes: the opening of the BS allowed freshwater anomalies in the North Atlantic convection region (CR) to flush into the Pacific 
(through the BS), thereby restarting convection and increasing oceanic and atmospheric temperatures in the NA. Also, as we shall see, limiting the transport entering the Atlantic raises the atmospheric temperature above the NA.

\section{b. Present study}

By incorporating the island rule as in DN04, we shall extend SN08's closed BS analytical approach to an open BS situation (Figs. 2 and 3). The NA will be viewed as a box that receives warm, salty water from the Southern Ocean and cold, fresh water from the Pacific through the BS. Deep water is formed in accordance to the salinity of the box and the heat flux to the atmosphere. Using this model, we will show that the opening of the BS and the increase in mean oceanic and atmospheric temperature are connected beyond a mere coincidence.

In section 2 we introduce the new model, which is no more than a blend of the DN04 and the SN08 models. Even so, the results of the blend are far from trivial. There is a limited (unavoidable) overlap of the material presented here with that recently presented in SN08 because an attempt has been made to make the present paper self-contained. Within the NA box, the model conserves mass, heat, and salt. A convection condition is used to allow movement of water out of the box into the deep layer. As in SN08, the part of the model which is the most difficult to understand is probably the ocean-atmosphere coupling via the Ekman layers. The concerned reader is advised to look at it merely as the plausible requirement that the mass transport (of the flows participating in the convection-induced heat exchange process) in the atmosphere and ocean be the same.

Although the resulting governing equations for the blended model are algebraic, they cannot be easily solved because they form a nonlinear system (with or without the elimination of some of the unknowns). Consequently, in section 3 we use an iteration scheme, initially assuming a small transport $Q_{2}$ from the Pacific through the BS compared to $Q_{1}$, the transport entering the Atlantic from the south. (Note that our conventional notation is defined both in the text and the appendixes.) This assumption (valid when $S_{1}-S \ll S-$ $S_{2}$, where $S_{1,2}$ are the salinities of the incoming waters and $S$ is the salinity of the convecting water) allows us to linearize the algebraic equations by initially setting $Q_{2}=0$ in all equations except the salt conservation equation. Then $Q_{2}$ is calculated using this salt conservation equation, and the process is then repeated until the solution converges. We ultimately find the change between a nonconvective closed BS and a convective
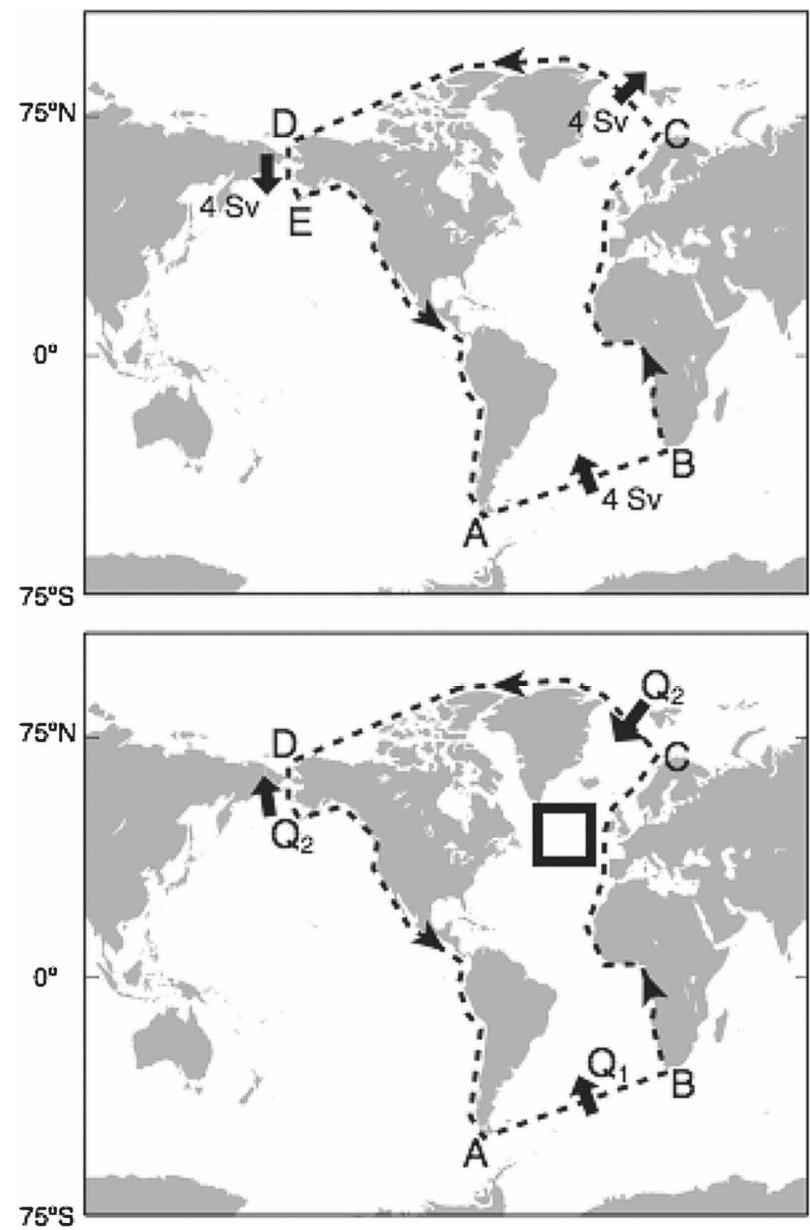

FIG. 2. (top) Island rule calculation of the no-NADW formation open BS geography. The integration is done in a counterclockwise manner along the dashed line. It indicates that in the absence of NADW formation, $4 \mathrm{~Sv}$ (of upper ocean water) would be forced in the South Atlantic. This $4 \mathrm{~Sv}$ (primarily caused by strong Southern Ocean winds) would exit the NA through cross section CD and then through the Arctic and the open BS. The winds over the Arctic and NA are so weak compared to the SO winds that altering the integration path in the Arctic makes virtually no difference at all. (Adapted from DN04.) (bottom) Present island rule calculation for the NA with NADW formation. Here, $Q_{1}$ and $Q_{2}$ are the upper layer (above Atlantic topography) transports into the Atlantic from the south and north, respectively. The convection region in the NA is outlined in solid black-this is the box whose details are shown in Fig. 3. Note that the direction of the flow through the BS reverses when the NADW formation ceases.

open BS ocean and atmosphere temperature to be $3^{\circ} \mathrm{C}$ (ocean) and $23^{\circ} \mathrm{C}$ (atmosphere).

\section{Governing equations for the coupled analytical model}

As mentioned, the model is a blend of two earlier models, the coupled ocean and atmosphere closed BS 


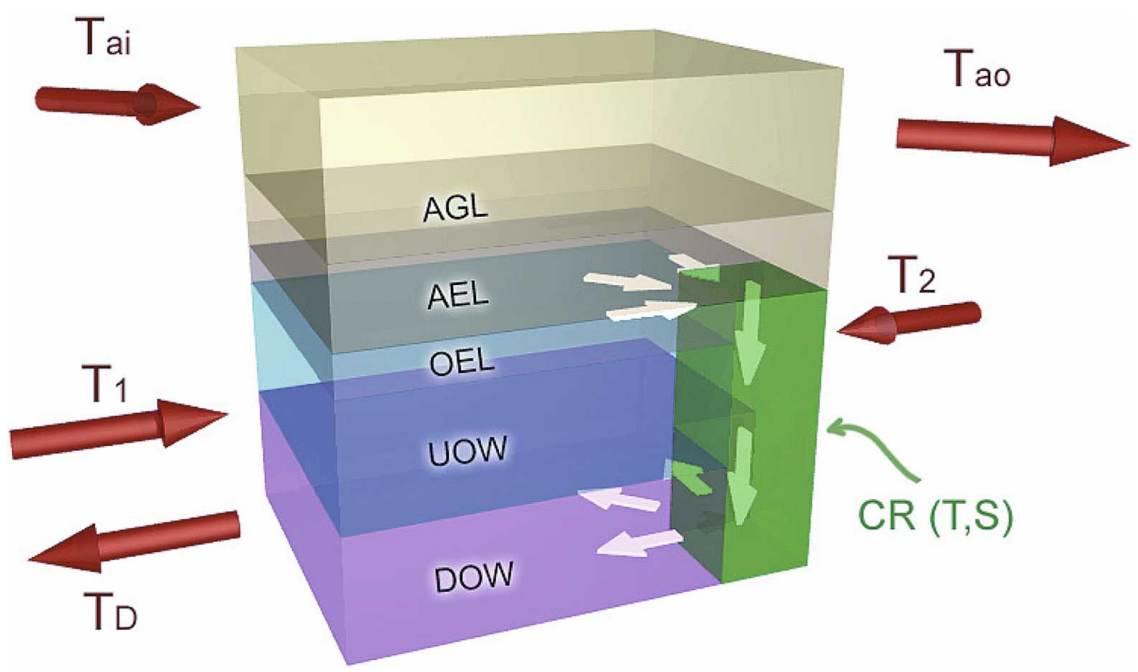

FIG. 3. A 3D view of the coupled dynamical-box model of the NA. This is a close-up of the black square shown in lower panel of Fig. 2. AGL indicates the atmospheric geostrophic layer above the atmospheric Ekman layer (AEL). OEL indicates the oceanic Ekman layer, UOW the upper ocean water just below, DOW the deep ocean water that has been convected and sunk from the upper ocean, CR the convection region where the downward transport is $W, T_{a i}$ and $T_{a o}$ are respectively the temperatures of the entering and exiting air over the NA box, $T_{1}$ the temperature of the water entering the North Atlantic box from the south, $T_{2}$ the temperature of the water originating in the BS and entering the North Atlantic box from the north, and $T_{D}$ the temperature of the water which has been convected and is now below the North Atlantic box (the returning below-topography southward flow). The symbolic "elevator" (i.e., the green $\mathrm{CR}$, much smaller than the box) represents convecting water sinking from both the OEL and the UOW to the DOW.

model of SN08 and the island-rule implementation of DN04. The blending of the two models enables us to use a coupled model with an open BS and thus determine the temperature changes associated with opening the BS. Neither of the two components is trivial, so despite the simple mathematics, the combined outcome presented here is fairly involved. In what follows, we present the combined model without going through the difficulties of its individual components. Some potentially nontrivial issues, such as the shallowness of the BS, the neglect of radiation, and the counterintuitive aspects of the heat exchange, which have been discussed in detail in these earlier models, are not even mentioned here. The reader who is interested in the details is advised to refer to the descriptions of these models before proceeding. The reader who is only interested in the results, on the other hand, should be able to find what she or he needs in the present article.

We are compelled, however, to make a few general notes regarding both DN04 and SN08. First, as in SN08 and DN04, there is no upwelling within the Atlantic because, as the observations suggest, most of the upwelling is taking place outside the limits of the Atlantic Ocean. In our scenario, MOC water enters the Atlantic from the south above the topography and exits (south- ward) below the topography. Second, again as in SN08, with the exception of the island rule, none of our governing equations hold for the collapsed "off" state. During the collapsed state, there is no convection, so there is no applicable "convection condition" and no heat exchange equation. Because the system of equations holds only in the noncollapsed state, the numerical values for the collapsed state were chosen from proxies, not from our solution. Third, recall that SN08 argued that radiation is unimportant for turning convection on and off; this was recently put on a firmer ground by Nof et al. (2008).

\section{a. Island rule implementation}

We shall make use of what DN04 termed the thermodynamic island rule, which is a minor modification of the original island rule (Godfrey 1989), brought about through the use of a Boussinesq fluid where one allows for density differences within the upper layer. Sinking is allowed east of the island and the equations are integrated to a fixed depth, assuming a steady state (see, e.g., Nof 2000). For clarity, the DN04 procedure is briefly mentioned below. Using the linearized Boussinesq momentum equations for a continuously stratified fluid and integrating them from the surface to a 
fixed depth $H$ (not necessarily a level of no motion) below the Ekman layer (to ensure zero stress) but above Atlantic bottom topography (say, $1500 \mathrm{~m}$ or so) gives us

$$
\begin{aligned}
-\rho_{0} f V & =-\frac{\partial P}{\partial x}+\tau^{x} \quad \text { and } \\
\rho_{0} f U & =-\frac{\partial P}{\partial y}+\tau^{y}-R V,
\end{aligned}
$$

where $\rho_{0}$ is the mean water density; $f$ is the Coriolis parameter; $U$ and $V$ are the depth-integrated zonal and meridional velocities, respectively; $P$ is the depthintegrated pressure (from the free surface to some fixed depth $H$ above the topography); $\tau^{x}$ and $\tau^{y}$ are the surface wind stresses in the $x$ and $y$ directions, respectively; and $R$ is a frictional parameter. Because our contour integral does not pass through the convection zone (Fig. 2), where there are strong vertical velocities, it does not make any difference if we make the level-ofno-motion assumption or not. Nevertheless, the levelof-no-motion assumption does not have to be made to derive our application of the island rule. All that is required is that the pressure be continuous along the contour. This is potentially violated across the BS because its sill depth is merely $55 \mathrm{~m}$. However, the $\sim 1 \mathrm{~Sv}$ $\left(1 \mathrm{~Sv} \equiv 10^{6} \mathrm{~m}^{3} \mathrm{~s}^{-1}\right)$ that goes through the strait is so much smaller than the hydraulic control limit that we assume the pressure to be continuous across it even below sill level. The related neglect of form drag and torque potentially exerted by the BS sill (which penetrates into the upper layer) was discussed at length by DN04 and need not be repeated here. (Recall, however, that torque and form drag come about though a discontinuous pressure across the sill.)

Integrating (2.1) along $\mathrm{AB}$ and $\mathrm{CD}$ (Fig. 2) and (2.2) along $\mathrm{BC}$ and $\mathrm{DA}$, then adding the four equations, eliminates the pressure, such that

$$
\rho_{O}\left(-f_{1} Q_{1}-f_{2} Q_{2}\right)=\oint_{\tau^{r}} d r,
$$

where the subscripts 1 and 2 refer to the southern and northern island tips, respectively, and $\oint \tau^{r} d r$ is the counterclockwise integrated wind stress along the path. Thus, $Q_{1}$ is the upper layer's equatorward transport entering the Atlantic from the south and $Q_{2}$ is the upper layer's equatorward transport entering the Arctic from the north. As in DN04, we assume that compared to the MOC transport, the mixing-induced upwelling and downwelling (just above the topography) within the limits of the Atlantic and Arctic are small, so $Q_{1}$ and $Q_{2}$ can also be taken to be the upper transports into the convection box shown in Fig. 2. This convection box contains a significant part of the NA and represents both the upstream region where the Ekman layers "prepare" the ocean for convection and the actual area of the convection itself $[\sim O(1 \mathrm{~km})$, much smaller than the box]. Fig. 3 is a close-up view of the convection box and shows both the "preparation region" and the actual convection region. The various temperatures of the transports going in and out of the box are also shown. Equation (2.3) is the only equation (for the additional unknown $Q_{2}$ ) that we will add to those of SN08.

In the above scenario, the convecting water flows southward (out of the Atlantic) below the topography. In the case of no convection $\left(W=0 ; Q_{1}=-Q_{2}\right.$, where $W$ is the total volume flux of the sinking water), (2.3) reduces to

$$
Q_{1}=\oint_{\tau^{r} d r / \rho_{0}}\left(f_{2}-f_{1}\right)
$$

which, for present-day winds, gives 3.9 Sv (DN04). Most of this transport comes about because of the strong southern winds along $\mathrm{AB}$, as opposed to the weak compensating northern winds along CD (see Fig. 2). Mass conservation within the North Atlantic box is

$$
W=Q_{1}+Q_{2}+F_{F},
$$

where $F_{F}$ is the freshwater flux.

\section{b. The thermodynamic relations and Ekman coupling}

The basic salt and heat equations for the closed BS as given by SN08 are also applicable here in the open BS case, except that the flow through the BS must be included. The salt equation is

$$
Q_{1} S_{1}+Q_{2} S_{2}=W S=\left(Q_{1}+Q_{2}+F_{f}\right) S,
$$

which simplifies to

$$
Q_{1}\left(S_{1}-S\right)+Q_{2}\left(S_{2}-S\right)=S F_{F} .
$$

Here, $S$ is the salinity in the North Atlantic box, and $S_{1,2}$ are the salinities of $Q_{1,2}$, respectively. We show the above, apparently trivial, simplification of (2.6) to (2.7) for a reason. It illustrates the following counterintuitive aspect: in contrast to the closed basin case (SN08) where an increase in $F_{f}$ means a reduced $S$, here an increase in $F_{f}$ does not necessarily mean a decrease in $S$. This is because an increase in $F_{f}$ can be accommodated by a steeper decrease in $Q_{2}$, which increases $S$.

The heat equation is

$$
Q_{1}\left(T_{1}-T\right)+Q_{2}\left(T_{2}-T\right)=\frac{A}{\rho_{w} C_{p w}}\left(F_{S}+F_{L}\right),
$$

where 


$$
\begin{aligned}
F_{S}= & \rho_{a} C_{p a} C_{S} U_{10}\left(T_{\text {mean }}-T_{\text {air }}\right), \\
F_{L}= & \rho_{a} L_{e} C_{L} U_{10} q^{*}\left(1-R_{H}\right)+\rho_{a} C_{L} U_{10} R_{H} \frac{C_{p a}}{\mathrm{Be}} \\
& \times\left(T_{\text {mean }}-T_{\text {air }}\right), \quad \text { and } \\
T_{\text {air }}= & \frac{T_{a i}+T_{a o}}{2}, \quad T_{\text {mean }}=\left[\frac{T+\frac{Q_{1} T_{1}+Q_{2} T_{2}}{Q_{1}+Q_{2}}}{2}\right] .
\end{aligned}
$$

In the above, $T$ is the convective oceanic temperature in the North Atlantic box (CR in Fig. 3); $T_{1,2}$ are the temperatures of $Q_{1,2}$ [i.e., the respective oceanic Ekman layer (OEL) and upper ocean water (UOW) coming from the south and north]; $A\left(\mathrm{~m}^{2}\right)$ is the area of the North Atlantic box, $\rho_{w}$ and $\rho_{a}\left(\mathrm{~kg} \mathrm{~m}^{-3}\right)$ are the densities of water and air, respectively; $C_{p w}$ and $C_{p a}\left(\mathrm{~J} \mathrm{~kg}^{-1} \mathrm{~K}^{-1}\right)$ are the specific heat capacities of water and air, respectively; $F_{S}$ and $F_{L}\left(\mathrm{~W} \mathrm{~m}^{-2}\right)$ are the sensible and latent heat fluxes, respectively, expressed in the manner defined by Hartmann (1994); $C_{S}$ and $C_{L}$ are constants; $U_{10}$ $\left(\mathrm{m} \mathrm{s}^{-1}\right)$ is the wind speed at $10 \mathrm{~m}$ above the surface; $q^{*}$ $\left(\mathrm{g} \mathrm{kg}^{-1}\right)$ is saturation specific humidity of the air; $L_{e}(\mathrm{~J}$ $\left.\mathrm{kg}^{-1}\right)$ is the latent heat of evaporation; $R_{H}$ is the relative humidity of the air; $\mathrm{Be}$ is the equilibrium Bowen ratio; $T_{\text {mean }}$ is the mean ocean temperature in the North Atlantic box (i.e., the average temperature of the two incoming waters and the sinking water); $T_{\text {air }}$ is the mean temperature of the air above the sea surface in the North Atlantic box; $T_{a i}$ and $T_{a o}$ are the respective temperatures of the incoming and outgoing air [i.e., the atmospheric Ekman layer (AEL) and atmospheric geostrophic layer (AGL) of the incoming and outgoing air) over the North Atlantic box; and $T_{D}$ and $S_{D}$ are, respectively, the temperature and salinity of the layer beneath the North Atlantic box (i.e., the deep ocean water (DOW) beneath the thermocline, created by the water sinking to the deep ocean). Note that $\left(Q_{1} T_{1}+\right.$ $\left.Q_{2} T_{2}\right) /\left(Q_{1}+Q_{2}\right)$ is the average temperature of the upper water (OEL and UOW) entering the box $\left(T_{w i}\right)$.

Also applicable is the linear convection condition

$$
T=T_{D}+\frac{\beta}{\alpha}\left(S-S_{D}\right),
$$

where $\alpha$ and $\beta$ are the expansion coefficients and, as mentioned, $T_{D}$ and $S_{D}$ are the temperature and salinity, respectively, of the deep layer beneath the upper ocean box and beneath the top of the Atlantic topography. The sixth model equation is the SN08 Ekman layer coupling approximation stating that upstream, away from the relatively small convection region within the box (see Fig. 3), the heat exchange between the ocean and the atmosphere is primarily between the Ekman layers. This simply implies that the horizontal atmospheric temperature changes are related to the horizontal oceanic changes through the heat capacities ratio, namely,

$$
T_{a o}-T_{a i}=\frac{C_{p w}}{C_{p a}}\left(T_{w i}-T_{w o}\right)=\frac{C_{p w}}{C_{p a}}\left(\frac{Q_{1} T_{1}+Q_{2} T_{2}}{Q_{1}+Q_{2}}-T\right) .
$$

In the above, $T_{a i}\left(T_{w i}\right)$ and $T_{a o}\left(T_{w o}\right)$ are the temperatures of the incoming and outgoing air (water) within the box. We shall associate $T_{w i}$ with the mean temperature of the upper incoming water (OEL and UOW), given by $\left(Q_{1} T_{1}+Q_{2} T_{2}\right) /\left(Q_{1}+Q_{2}\right)$, and $T_{w o}$ with the CR water temperature $T$.

Note that these Ekman flows take place upstream within the box where they merely prepare the ocean for convection to occur downstream in an area (the CR) much smaller than the box. Once convection sets in downstream, much larger flows are drawn in by the convection itself. Condition (2.12) can also be viewed simply as a plausible assumption that the convectioninduced mass fluxes of the ocean and atmosphere are the same. This equivalency can be verified by considering the analogous condition of (2.8) for the atmosphere, combining it with (2.8) and inserting the equal mass flux condition into the resulting combination. As in SN08, because the water-to-air specific heat capacity ratio is about four, the coupling condition essentially means that the atmospheric variations are about 4 times the oceanic variations but in the opposite direction (i.e., the atmosphere warms when the ocean cools and vice versa).

Above we have a set of six equations, (2.3), (2.5), (2.7), (2.8), (2.11), and (2.12), for the six unknowns $T, S$, $T_{a o}, Q_{1}, Q_{2}$, and $W$, which are the only endogenous variables in the problem. Although these equations are algebraic, they are nonlinear in the sense that they involve multiplications of unknown variables. Attempts to eliminate some of the variables to form a reduced and more compact set of equations for one or two unknowns produces highly nonlinear equations that cannot be handled analytically. Hence, an iteration scheme is employed in the next section. Note that because there is no convection in the off state, the above set of equations is not valid in that limit.

As expected, in the limit of no ocean-atmosphere coupling, the above model reduces to the familiar convection and wind-only model of DN04. Similarly, in the limit of no wind stress along the integration contour (Fig. 3a) but with a nonzero $U_{10}$ within the basin and no convection, the model reduces to the Ekman coupling condition. When the island-wind constraint is replaced 
by a geostrophic control condition at the BS (Toulany and Garrett 1984) and the coupling is removed, the model reduces to a regime-model for the convection (Shaffer and Bendtsen 1994). In the limit of no wind along the integration contour, the convection cannot draw water from other oceans and the convectively sinking water must be compensated for by upwelling within the limits of the Atlantic itself (absent from our model). The validity of all of these limits indicates that the model is self-consistent.

\section{Open Bering Strait}

For our iteration scheme, it is first assumed that $Q_{2}$ is small compared to $Q_{1}$, which allows us to first ignore $Q_{2}$ in all equations except the salt conservation equation, thereby reducing the system to a linear set of equations. This immediately gives $Q_{1}$ [from (2.3)], which together with a substitution of (2.12) into (2.8) gives $T$. We then use $T$ and (2.11) to get $S$ and then go back to (2.7) to get a new value for $Q_{2}$. We repeated this process numerically 50 times and verified that our results converged. Following SN08, our chosen LGM parameters are as follows: $\oint \tau^{r} d r=9.36 \mathrm{kgs}^{-2}$ (integrated $40 \mathrm{yr}$ of present-day NCEP annual winds (NCEP winds were provided by the NOAA-CIRES Climate Diagnostics Center; see http://www.cdc.noaa.gov.) around the Americas), $f_{1}=-1 \times 10^{-4} \mathrm{~s}^{-1}, f_{2}=1.4 \times 10^{-4} \mathrm{~s}^{-1}, A=$ $10^{12} \mathrm{~m}^{2}$ (corresponding to $1000 \times 1000 \mathrm{~km}^{2}$ ), $\rho_{w}=1000$ $\mathrm{k} \mathrm{gm}^{-3}, \rho_{a}=1.5 \mathrm{k} \mathrm{gm}^{-3}, C_{p w}=4000 \mathrm{~J} \mathrm{~kg}^{-1} \mathrm{~K}^{-1}, C_{p a}=$ $1030 \mathrm{~J} \mathrm{~kg}^{-1} \mathrm{~K}^{-1}, \alpha=5 \times 10^{-5} \mathrm{~K}^{-1}, \beta=8 \times 10^{-4}$ $\mathrm{psu}^{-1}, L_{e}=2.5 \times 10^{6} \mathrm{~J} \mathrm{~kg}^{-1}, C_{s}=9 \times 10^{-4}, C_{L}=$ $1.35 \times 10^{-3}, U_{10}=5.0 \mathrm{~m} \mathrm{~s}^{-1}, R_{H}=0.76, \mathrm{Be}=0.6$, $q^{*}=10 \mathrm{~g} \mathrm{~kg}^{-1}, T_{a i}=-5^{\circ} \mathrm{C}, T_{1}=18^{\circ} \mathrm{C}, T_{2}=2^{\circ} \mathrm{C}, T_{D}$ $=1.5^{\circ} \mathrm{C}, S_{1}=36.15 \mathrm{psu}, S_{2}=34.00 \mathrm{psu}, S_{D}=35.4 \mathrm{psu}$, and $0 \leq F_{F} \leq 3 \times 10^{4} \mathrm{~m}^{3} \mathrm{~s}^{-1}$.

All six calculated variables $\left(S, T, T_{a o}, Q_{1}, Q_{2}\right.$, and $W$ ) as well as the heat flux $F_{H}$ are plotted as a function of the freshwater flux in Fig. 4. For increasing freshwater $F_{F}$, salinity $S$ decreases, which in turn decreases temperature $T$, convection $W$, heat flux to the atmosphere $F_{H}$ and transport from the south $Q_{1}$. However, outgoing air temperature increases because $\Delta T=T_{1}-T$ increases (thereby increasing the temperature gradient across the sea surface), even though the heat flux decreases. This merely reflects $Q_{1}$ 's dominance over $\Delta T$ in the heat flux term: $Q_{1}$ decreases more rapidly than $\Delta T$ increases. The flow through the BS $\left(Q_{2}\right)$ decreases to zero at the critical freshwater flux (discussed later in section 4), and reverses direction (i.e., flows into the Pacific) for $F_{F}>0.026 \mathrm{~Sv}$.
Because the limit of the right-hand side of (2.8) goes to zero when $U_{10}$ goes to zero, it follows that for each freshwater flux, there is a critical $U_{10}$ below which the convection collapses because there is not enough wind to enable the required heat transfer to the atmosphere. Alternately, we can say that for each $U_{10}$ there is a critical freshwater flux beyond which the convection collapses. The solution, for our chosen numerical values, becomes invalid for freshwater fluxes greater than the critical flux (Fig. 4, solid dots). The variables $q^{*}, R_{H}$, and $\mathrm{Be}$ are all dependent on $T_{\text {air }}$, but it is simpler (and inconsequential) to use a fixed value for $T_{a i}$ and then verify in the end the validity of this approach.

\section{Critical freshwater flux}

We will now examine the critical freshwater flux where convection in the North Atlantic is arrested, reversing the flow through the BS (i.e., water flows into the Pacific). Note that there are actually two, distinctly different, critical freshwater fluxes $\left(F_{F c}\right)$. The first corresponds to no convection $(W=0)$ and results from the surface flow exiting the Atlantic via the BS rather than sinking. The second is caused by the breakdown of the ocean-air heat flux process because of weak winds. The solid dots in the earlier figures correspond to the second scenario. We shall see that although the two are different, they give similar values for the critical freshwater fluxes. For $W=0$ we find, after a fair amount of algebra,

$$
Q_{2}=\frac{S_{1} F_{F c}}{\left(S-S_{1}\right)}, \quad F_{F c}=\frac{Q_{\tau}\left(S_{1}-S\right)}{\left[S_{1}+f_{1}^{*}\left(S_{1}-S\right)\right]},
$$

and a quadratic in $T$,

$C_{7} T^{2}+\left(C_{6}-C_{2}+C_{4}\right) T+\left(C_{3}-C_{1}+C_{5}\right)=0$,

where

$$
\begin{aligned}
& C_{1}=Q_{\tau} T_{1}\left(S_{D}-\frac{\alpha}{\beta} T_{D}\right) \\
& C_{2}=Q_{\tau} \frac{\alpha}{\beta} T_{1}-Q_{\tau}\left(S_{D}-\frac{\alpha}{\beta} T_{D}\right) \\
& C_{3}=L_{e} C_{L} q^{*}\left(1-R_{H}\right)\left[\left(1-f_{2}^{*}\right)\left(S_{D}-\frac{\alpha}{\beta} T_{D}\right)+f_{2}^{*} S_{1}\right]
\end{aligned}
$$

$$
C_{4}=L_{e} C_{L} q^{*}\left(1-R_{H}\right)\left(1-f_{2}^{*}\right) \frac{\alpha}{\beta}
$$



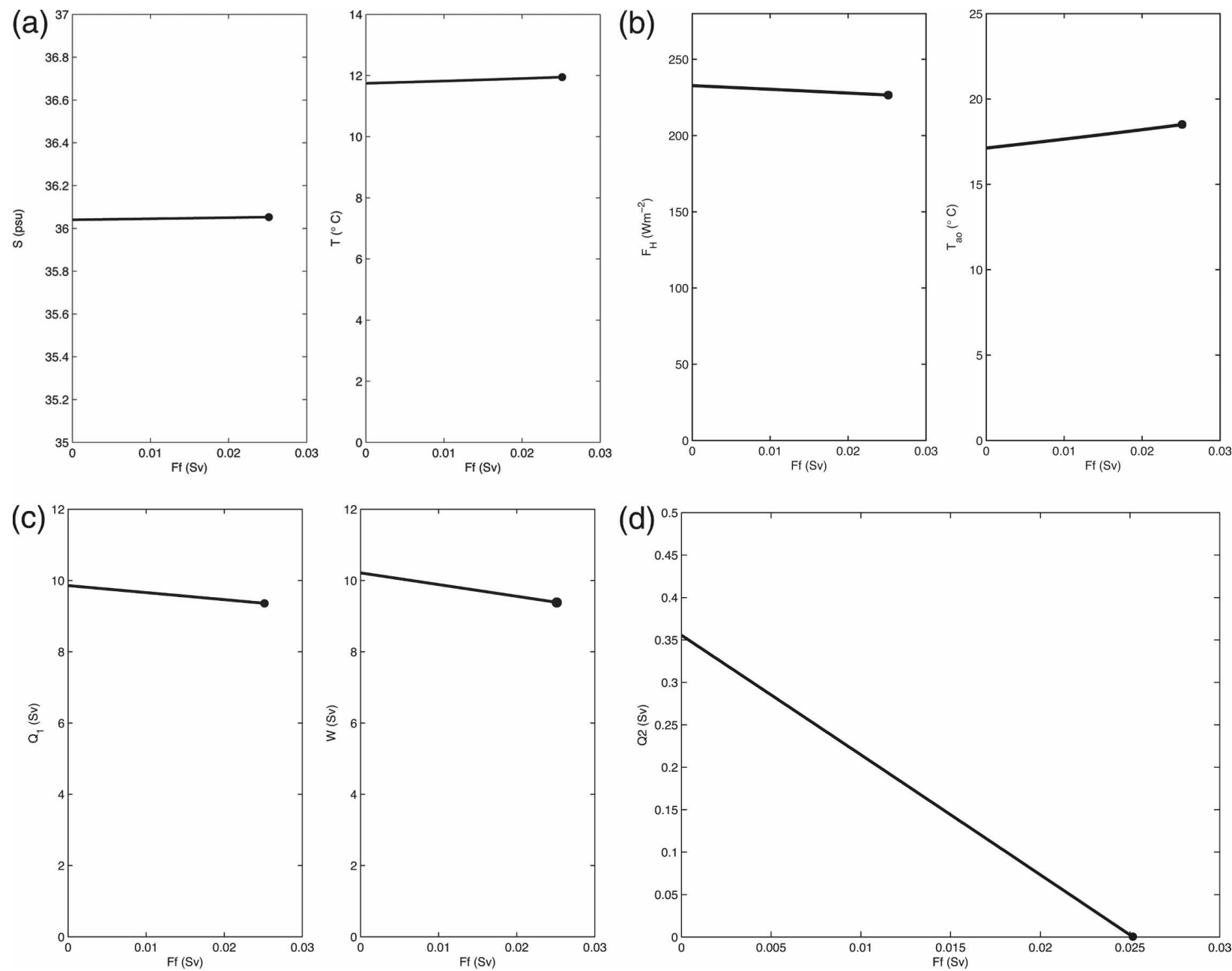

FIG. 4. (a) Open BS solution as a function of freshwater flux $F_{F}(\mathrm{~Sv})$. (left) The convective salinity (psu) in the NA box, $S$; (right) the convective ocean temperature $\left({ }^{\circ} \mathrm{C}\right), T$. Here, $U_{10}=5 \mathrm{~m} \mathrm{~s}^{-1}$. The solid dots indicate where the solution collapses (i.e., where the freshwater flux is so great that convection in the NA box can no longer take place). (b) (left) Heat flux out of the NA box (into the atmosphere), $F_{H}\left(\mathrm{~W} \mathrm{~m}^{-2}\right)$ and (right) the outgoing air temperature, $T_{a o}\left({ }^{\circ} \mathrm{C}\right)$. Note that as in SN08, the outgoing air temperature increases with increasing freshwater flux and a decreasing MOC. (c) (left) MOC transport from the south into the NA box, $Q_{1}$ (Sv) and (right) the sinking water out of the NA box, $W(\mathrm{~Sv})$. (d) The transport of water through the BS, $Q_{2}(\mathrm{~Sv})$. Here, the difference between the two perturbations appears to be relatively large, but it is really small (as it should be) compared to the MOC transport.

$$
\begin{aligned}
& C_{5}=\left(C_{L} R_{H} \frac{C_{p a}}{\mathrm{Be}}+C_{p a} C_{S}\right)\left\{-\left(T_{a i}+\frac{C_{p w}}{2 C_{p a}} T_{1}\right)\left[\left(S_{D}-\frac{\alpha}{\beta} T_{D}\right)\left(1-f_{2}^{*}\right)+f_{2}^{*} S_{1}\right]\right\}, \\
& C_{6}=\left(C_{L} R_{H} \frac{C_{p a}}{\mathrm{Be}}+C_{p a} C_{S}\right)\left\{\left(1+\frac{C_{p w}}{2 C_{p a}}\right)\left[\left(S_{D}-\frac{\alpha}{\beta} T_{D}\right)\left(1-f_{2}^{*}\right)+f_{2}^{*} S_{1}\right]-\left[T_{a i}+\frac{C_{p w}}{2 C_{p a}} T_{1}\right] \frac{\alpha}{\beta}\left(1-f_{2}^{*}\right)\right\},
\end{aligned}
$$

$C_{7}=\left(C_{L} R_{H} \frac{C_{p a}}{\mathrm{Be}}+C_{p a} C_{S}\right) \frac{\alpha}{\beta}\left(1-f_{2}^{*}\right)\left(1+\frac{C_{p w}}{2 C_{p a}}\right)+Q_{\tau} \frac{\alpha}{\beta}$

This quadratic has two roots; although both are mathematically valid, only one is physically valid. [The other (unphysical) root produces $T_{c}=-210^{\circ} \mathrm{C}$, with $Q_{1}$ and $W$ negative, which is consistent with upwelling instead of downwelling and southward surface flow instead of northward flow.] The physically valid solution of $T_{c}=13.4^{\circ} \mathrm{C}$ is higher than the CEREGE alkenone ocean temperature at the convection site during Hein- 
rich events. Using this temperature in (2.11) to get an equivalent salinity, the critical freshwater flux for $W=$ 0 is found, from (4.1), to be $0.05 \mathrm{~Sv}$. This is about twice the value associated with the breakdown point of the iteration method shown with the solid dot in Fig. 4. As mentioned, the two critical conditions should not necessarily be the same because the two fluxes correspond to two different physical situations. One criticality is associated with $W=0$, whereas the other corresponds to insufficient wind for the heat fluxes. Finally, we note that when we compare the above critical value to the result of $0.17 \mathrm{~Sv}$ in DN04, we find that our critical freshwater flux is within $24 \%$ of theirs.

\section{Discussion}

Regardless of whether the BS is open or closed, when the MOC is active, warm water from the south is transported to the northern North Atlantic (NA), where it cools by releasing heat to the atmosphere and sinks as North Atlantic Deep Water (NADW). Our simplified view of the climate history before and after the BS opened goes as follows. During the last glacial period when the BS was closed, the Northern Hemisphere convection in the NA was intermittent (because of freshwater perturbations), which in turn reduced the mean transport of heat from the south, thus lowering the mean oceanic and atmospheric temperature in the NA. During the end of the last glaciation (Younger Dryas) the MOC was completely shut off (just as it was during earlier Heinrich events). As deglaciation set in at the end of the Last Glacial Maximum (LGM), a rise in global mean temperature caused the extensive continental ice sheets to melt and break up into icebergs that surged into the surrounding oceans.

A large portion of these icebergs ended up in the Arctic, entering at points in the Canadian Archipelago, where the circulation (in the Canadian Basin) forced them toward the still-closed BS (Sandal and Nof 2008 b). Once sea level rose sufficiently to open the BS, forcing the sea level to be continuous around the Americas, approximately $4 \mathrm{~Sv}$ of upper ocean water would attempt to flush through the Arctic and BS into the Pacific (see Nof and Van Gorder 2003; DN04; Fig. $2)$. At that point, the MOC is fairly quickly reactivated ( $\sim 250 \mathrm{yr}$, which is the 4-Sv flushing time of the Arctic and North Atlantic) because the freshwater anomaly, which forced it off in the first place, has been flushed out. By incorporating the island rule into our recently developed coupled ocean-atmosphere model for the closed NA (SN08), we recreated the mean temperature increase in the ocean and atmosphere, as seen in the CEREGE alkenone record (Bard 2002) and the GISP 2
Greenland ice core record. The island rule brings into the model an additional equation and an additional unknown, the volume flux through the BS.

We presented calculations of the ocean temperature at the convection site, the outgoing air temperature, the salinity at the site, the flow from the south, the flow from the north, the convection, and the latent and sensible heat fluxes as functions of the freshwater flux. The results are displayed in Figs. 4, 5, and 6. Our temperature-dependent latent and sensible heat fluxes allowed us to do the calculations for a convection that is dependent on temperature and, therefore, on freshwater flux. This further permits us to calculate the change in the outgoing air temperature between convective and nonconvective regimes (Fig. 6).

Although it is relatively easy to understand why an open convective BS state (Holocene) is warmer than the closed nonconvective state (Younger Dryas), it is not a trivial matter to illustrate why, even with an active convection, an atmospheric temperature rise is associated with the opening of the BS. The reader is requested to bear with us as we go through the explanation in section $5 b$ below. As demonstrated in SN08, the dependence of the outgoing air temperature on a reduction or an increase in the MOC is counterintuitive and contradicts what many numerical models show (e.g., Stouffer et al. 2006; Stocker 2002). When the heat flux is dominated by latent and sensible heat, a decrease in the MOC transport causes warming in the atmosphere and cooling of the ocean. (The warming is associated, however, with a smaller amount of air going through the heat exchange with the ocean.) Given the 1:4 specific heat capacity ratio (of air and water), this implies that opening the strait while an MOC is active warms the atmosphere significantly and cools the ocean slightly. This is elaborated on below.

\section{a. Freshwater fluxes}

Our critical freshwater fluxes are smaller than those usually found; this is primarily because we used LGM values. If modern-day values are used instead of LGM values, the critical freshwater flux increases from about 0.05 to $0.12 \mathrm{~Sv}$, which is a typically quoted value (see, e.g., Rahmstorf 2006). Hence, our results do not conflict with Curry and Mauritzen's (2005) observations (based on hydrographic data in the convective region of the North Atlantic and Labrador Sea) of a 0.06-Sv freshwater flux diluting the northern North Atlantic over the past $40 \mathrm{yr}$, suggesting that such a freshwater flux does not cause an MOC collapse.

Numerical models (e.g., Stouffer et al. 2006; Reason and Power 1994; Goosse et al. 1997; Wadley and Bigg 2002; Hasumi 2002) on the other hand, mostly use 


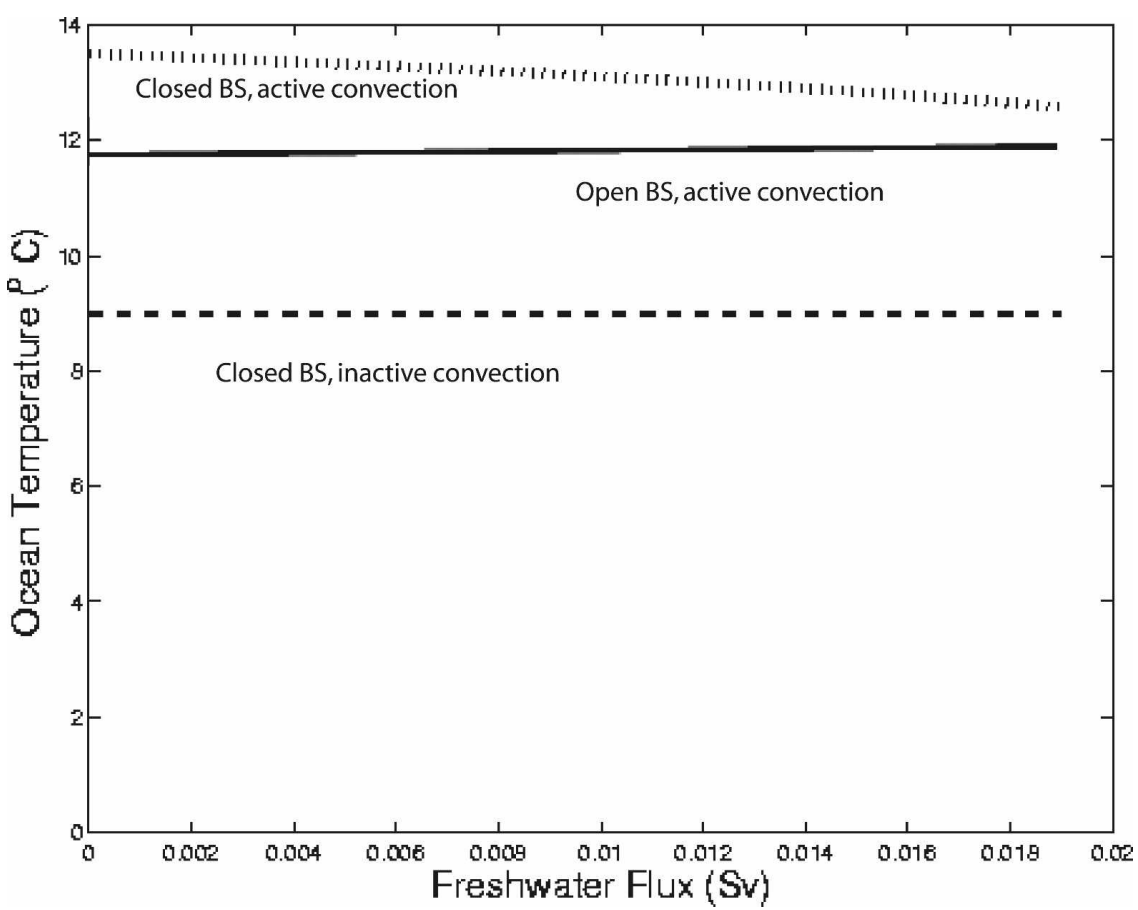

FIG. 5. Ocean temperature vs the freshwater flux. Convective open BS ocean temperature in the NA box is shown with the solid line. The nonconvecting closed BS temperature (dashed line) and the convecting closed BS scenario (dotted line) are also shown. The convecting and nonconvecting closed BS ocean temperatures are those of SN08. Information from this figure (with zero freshwater flux) was used to construct the horizontal lines in Fig. 1, which are probably easier to understand than the (more complete) information displayed here. Note that because LGM values have been used for all calculations, the increase in the incoming water $T_{1}$ as the climate warmed to Holocene values is not included in the calculations.

present-day values and still require a freshwater flux greater than $0.1 \mathrm{~Sv}$ to terminate convection in the North Atlantic. There are three reasons for the difference between our critical freshwater flux and those of the numerical models. First, our chosen LGM values have put our system closer to its point of breakdown, thus requiring a smaller freshwater flux to kill the convection. Second, advection of water through the convection region is not incorporated in our analytical model but is present in numerical models. Hence, for the same effect, less fresh water needs to enter the system in our model. Third, the relatively large diffusivities typically used in numerical models (vertical diffusivity of $0.3-1.0$ $\mathrm{cm}^{2} \mathrm{~s}^{-1}$ and horizontal diffusivity of $10^{7} \mathrm{~cm}^{2} \mathrm{~s}^{-1}$ ) introduce an added flow through the system (1-5 Sv), which diffuses the freshwater anomalies. Again, this means that numerical models require a larger critical freshwater flux to shut off convection.

\section{b. Properties of the solution}

Our general goal was to compare a convecting open $\mathrm{BS}$ with a nonconvecting closed $\mathrm{BS}$, equivalent to the early Holocene and the Younger Dryas, respectively. The GISP 2 record indicates an atmospheric temperature rise very close to our $23^{\circ} \mathrm{C}$ calculation (Figs. 1 and 4). The CEREGE alkenone (Bard 2002) records indicate a $6^{\circ} \mathrm{C}$ ocean temperature change between the Younger Dryas and the early Holocene, which is somewhat larger than our result of $3^{\circ} \mathrm{C}$ (see Fig. 5 and the blue horizontal lines in Fig. 1). (Note that, following SN08, oceanic and atmospheric temperatures for a nonconvecting closed BS were taken from the lowest temperature dips associated with the Heinrich events shown in Fig. 1.) The above $3^{\circ} \mathrm{C}$ difference between the "predicted" and actual oceanic temperatures rise is probably because we used the LGM values in all the calculations, implying that the mean oceanic temperature change, due to the general warming, is not included in our calculation. Likewise, this is probably the reason why our solution for an active convection shows that a closed BS produces a warmer ocean temperature than an open BS. If we were to modify our chosen temperature and salinity values to better suit Holocene conditions, the temperature at the site for an open BS 


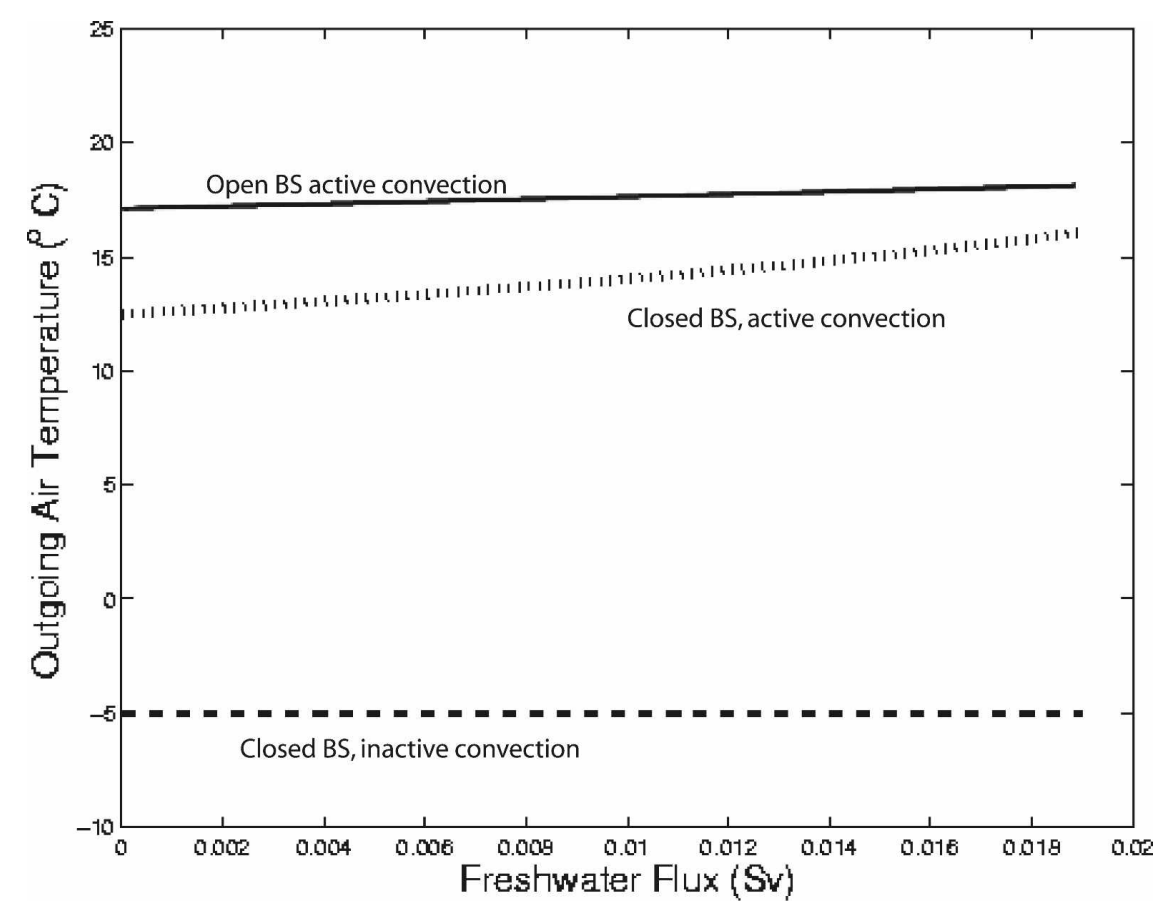

FIG. 6. Same as in Fig. 5, but for the outgoing air temperature, and outgoing open BS air temperature over the NA box $\left(T_{a o}\right)$ is shown with the solid line. As in Fig. 5, information from this figure (with zero freshwater flux) was used to construct the horizontal lines in Fig. 1.

(and an active convection) would increase to $5^{\circ} \mathrm{C}$ (ocean) and $30^{\circ} \mathrm{C}$ (atmosphere), both of which are above those found for a closed BS (Figs. 5 and 6).

An aspect that is more difficult to see is why both the atmosphere and ocean are warmer with an open BS than with a closed BS even when the convection is active in both cases. There are two reasons why the atmosphere should be warmer. First, the open BS allows the wind to control the transport from the south and effectively reduce $Q_{1}$ in half (compared to the closed BS). Although our intuition tells us that lowering the MOC should cool the atmosphere, SN08 have demonstrated that what happens is the opposite: reducing the MOC (by increasing freshwater flux) warms the atmosphere and slightly cools the ocean. The same effect is found in our present model: reducing $Q_{1}$ lowers the ocean temperature slightly but significantly increases the atmospheric temperature. Second, as expected, the oceanic temperature and salinity at the site decrease as cooler and fresher water from the Pacific enters the North Atlantic box from the north. Again, in line with the SN08 solution, this further warms the atmosphere and slightly cools the ocean.

\section{Summary}

Using a new model, which is a blend of the DN04 model and the SN08 model, we demonstrated the following points:
- With an active MOC and an open BS under glacial conditions, the wind allows merely $8 \mathrm{~Sv}$ to enter the South Atlantic from the Southern Ocean. This is about half the amount that could enter with a closed BS and an active convection (17 Sv).

- A comparison of an active convection with an open BS (Holocene) to an inactive convection with a closed BS (Younger Dryas) shows that our modeled atmosphere is warmer by $22^{\circ} \mathrm{C}$ and the modeled ocean is warmer by $3^{\circ} \mathrm{C}$. Both are in agreement with the record (Fig. 1, shown by the blue arrows), but the atmosphere is in somewhat better agreement than the ocean.

- Similarly, a comparison of a modeled active convection with an open BS (Holocene) to a modeled active convection with a closed BS (non-Heinrich states during glaciation) indicates that the modeled atmosphere is about $5^{\circ} \mathrm{C}$ warmer, whereas the modeled ocean is about $2^{\circ} \mathrm{C}$ cooler. Here, the modeled atmospheric change associated with the opening agrees very well with the record, but the modeled ocean behaves oppositely sense, probably because of our numerical choice of LGM values for the input parameters (rather than Holocene values) or because of the smallness of the ocean temperature variability.

- In the mean (i.e., a comparison of a mean glacial state in between the intermittent active and inactive convection, and a mean Holocene state with active con- 
vection), the modeled atmosphere warms by about $13^{\circ} \mathrm{C}$ and the modeled ocean warms by $1^{\circ} \mathrm{C}$. These predicted increases are shown with the black arrows in Fig. 1, indicating a reasonably good agreement.

Figures 5 and 6 show a $22^{\circ} \mathrm{C}\left(3^{\circ} \mathrm{C}\right)$ increase in the outgoing air (ocean) temperature between a nonconvecting closed BS (Younger Dryas) and a convecting open BS (Holocene). The limiting case of zero freshwater flux (most applicable to our application) is shown with blue arrows in Fig. 1. Another interesting comparison is that of the mean temperature rise associated with opening the BS, shown with black arrows in Fig. 1. Here, we also see a major dynamical change between an open and a closed BS state and a general agreement between our calculations and the record.

When comparing the calculated or observed values to a calculated increase in temperature due to a decrease in albedo $\left(8^{\circ} \mathrm{C}\right.$ according to Sandal 2006), it is evident that turning on convection allows temperature differences 3 times larger than do changes in albedo alone. This explanation also fits with the abruptness of the increase, which could not have been achieved by albedo alone. Note that the atmospheric temperature record was taken from ice cores situated much farther north than our chosen box, so we can only compare temperature differences (not absolute values) to the observations. Furthermore, the continental ice sheets did not disappear completely at the beginning of the Holocene (Hu et al. 1999), so this $8^{\circ} \mathrm{C}$ can be seen as a maximum temperature increase due to albedo change.

In summary, most of the abrupt increase of the ocean and air temperature after the Younger Dryas is associated with a quick reactivation of the MOC in the North Atlantic. This quick reactivation is associated with the collapse of the ice dam at the Bering Strait, which allowed the freshwater anomaly to exit the Atlantic.

Acknowledgments. Stephen Van Gorder helped us a great deal with the numerical-iterative solution. The study was supported by the National Aeronautics and Space Administration under Grant NGT5-30513 and the National Science Foundation under Grants OPP/ ARC-0453846, OCE-0545204, and OCE-02421036.

\section{APPENDIX A}

\section{List of Symbols}

A area of North Atlantic box $\left(\mathrm{m}^{2}\right)$

$\alpha \quad$ temperature expansion coefficient $\left(\mathrm{K}^{-1}\right)$

$\beta \quad$ salinity expansion coefficient $\left(\mathrm{psu}^{-1}\right)$

Be Bowen ratio

$C_{p a} \quad$ heat capacity of air $\left(\mathrm{J} \mathrm{kg}^{-1} \mathrm{~K}^{-1}\right)$

$C_{p w} \quad$ heat capacity of seawater $\left(\mathrm{J} \mathrm{kg}^{-1} \mathrm{~K}^{-1}\right)$
$C_{S} \quad$ sensible heat flux constant

$C_{L} \quad$ latent heat flux constant

$f_{1,2} \quad$ Coriolis parameters along the southern and northern island tips (Fig. 2)

$F_{f} \quad$ freshwater flux into the convection region (Sv; Fig. 3)

$F_{F c} \quad$ critical freshwater flux (Sv)

$F_{S} \quad$ sensible heat flux out of convection region $\left(\mathrm{W} \mathrm{m}^{-2}\right)$

$F_{L} \quad$ latent heat flux out of convection region $\left(\mathrm{W} \mathrm{m}^{-2}\right)$

$F_{H} \quad$ total heat flux out of the convection region $\left(\mathrm{W} \mathrm{m}^{-2}\right.$ )

$g \quad$ gravitational constant $\left(\mathrm{m} \mathrm{s}^{-2}\right)$

$L_{e} \quad$ latent heat of evaporation $\left(\mathrm{J} \mathrm{kg}^{-1}\right)$

$q^{*} \quad$ saturation specific humidity $\left(\mathrm{g} \mathrm{kg}^{-1}\right)$

$Q_{1}, Q_{2} \quad$ southern and northern transport into the island basin $(\mathrm{Sv})$

$\tilde{Q}_{W} \quad$ oceanic Ekman layer transport through the NA box (Sv)

$\tilde{Q}_{A} \quad$ atmospheric Ekman layer transport through the atmospheric box $(\mathrm{Sv})$

$\rho_{a} \quad$ mean density of air over the convection region $\left(\mathrm{kg} \mathrm{m}^{-3}\right)$

$\rho_{w} \quad$ mean density of the water in the convection region $\left(\mathrm{kg} \mathrm{m}^{-3}\right)$

$\rho_{0} \quad$ mean ocean water density $\left(\mathrm{kg} \mathrm{m}^{-3}\right)$

$r \quad$ integration path

$R_{H} \quad$ relative humidity

$S \quad$ salinity of the water in the convection region (psu)

$S_{1}, S_{2} \quad$ salinities associated with the transports $Q_{1}$, $Q_{2}$ (psu)

$S_{D} \quad$ salinity of the deep layer (psu)

$U_{10} \quad$ mean speed of atmosphere at $10 \mathrm{~m}$

$W \quad$ net sink of water from the upper to the lower layer $(\mathrm{Sv})$

$\tau^{r} \quad$ wind stress in the direction $r$

$T$ temperature of the water in the convection region

$T_{1}, T_{2}$ temperatures associated with the transports $Q_{1}, Q_{2}\left({ }^{\circ} \mathrm{C}\right)$

$T_{D} \quad$ temperature of the deep layer $\left({ }^{\circ} \mathrm{C}\right)$

$T_{a i}, T_{a o}$ temperature of the incoming and outgoing air over the convection region $\left({ }^{\circ} \mathrm{C}\right)$

$T_{w i}, T_{w o}$ temperature of the incoming and outgoing water in the NA box $\left({ }^{\circ} \mathrm{C}\right)$

\section{APPENDIX B}

\section{Abbreviations}

AGL

AEL
Atmospheric Geostrophic Layer

Atmospheric Ekman Layer 


$\begin{array}{ll}\begin{array}{ll}\text { BS } \\ \text { CEREGE }\end{array} & \begin{array}{l}\text { Bering Strait } \\ \text { Centre Européen de Recherche et d'En- } \\ \text { seignement des Géosciences de l'Envi- } \\ \text { ronnement, Aix-en-Provence, France }\end{array} \\ \text { CR } & \begin{array}{l}\text { Convection Region } \\ \text { DOW }\end{array} \\ \text { Deep Ocean Water } \\ \text { LGSP 2 } & \text { Greenland Ice Sheet Project 2 } \\ \text { MOC } & \text { Last Glacial Maximum } \\ \text { NA } & \text { Neridional Overturning Cell } \\ \text { NADW } & \text { North Atlantic } \\ \text { OEL } & \text { Oceanic Ekman Layer } \\ \text { SO } & \text { Southern Oceanography } \\ \text { UOW } & \text { Upper Ocean Water } \\ \text { YBP } & \text { Years Before Present }\end{array}$

\section{REFERENCES}

Alley, R. B., P. U. Clark, P. Huybrechts, and I. Joughin, 2005: Ice-sheet and sea-level changes. Science, 310, 456-459.

Bard, E., 2002: Climate shock: Abrupt changes over millennial time scales. Phys. Today, 55, 32-38.

— , F. Rostek, J.-L. Turon, and S. Gendreau, 2000: Hydrological impact of Heinrich events in the subtropical northeast Atlantic. Science, 289, 1321-1324.

Blunier, T., and Coauthors, 1998: Asynchrony of Antarctic and Greenland climate change during the last glacial period. $\mathrm{Na}$ ture, 394, 739-743.

Bond, G., W. Broecker, S. Johnson, J. McManus, L. Labeyrie, J. Jouzel, and G. Bonani, 1993: Correlations between climate records from NA sediments and Greenland ice. Nature, 365, 143-147.

Boyle, E. A., 2000: Is the ocean thermohaline circulation linked to abrupt stadial/interstadial transitions? Quat. Sci. Rev., 19, $255-272$.

Broecker, W. S., 1994: Massive iceberg discharges as triggers for global climate change. Nature, 372, 421-424.

Cacho, I., J. O. Grimalt, C. Pelejero, M. Canals, F. J. Sierro, J. A. Flores, and N. Shackleton, 1999: Dansgaard-Oeschger and Heinrich events imprints in Alboran Sea paleotemperatures. Paleoceanography, 14 (6), 698-705.

Clark, P. U., N. G. Pisias, T. F. Stocker, and A. J. Weaver, 2002: The role of the thermohaline circulation in abrupt climate change. Nature, 415, 863-869.

Curry, R., and C. Mauritzen, 2005: Dilution of the northern North Atlantic Ocean in recent decades. Science, 308, 1772-1774.

De Boer, A. M., and D. Nof, 2004a: The exhaust valve of the North Atlantic. J. Climate, 17, 417-422.

$\longrightarrow$, and $-2004 \mathrm{~b}$ : The Bering Strait's grip on the Northern Hemisphere climate. Deep-Sea Res. I, 51, 1347-1366.

Dyke, A. S., J. E. Dale, and R. N. McNeely, 1996: Marine molluscs as indicators of environmental change in glaciated North America and Greenland during the last 18000 years. Geog. Phys. Quat., 50 (2), 125-184.

Godfrey, J. S., 1989: A Sverdrup model of the depth-integrated flow for the World Ocean allowing for island circulation. Geophys. Astrophys. Fluid Dyn., 45, 89-112.

Goosse, H., J. M. Campin, T. Fichefet, and E. Deleersnijder, 1997: Sensitivity of a global ice-ocean model to the Bering Strait throughflow. Climate Dyn., 13, 349-358.

Hartmann, D., 1994: Global Physical Climatology. Academic Press, $411 \mathrm{pp}$.

Hasumi, H., 2002: Sensitivity of the global thermohaline circulation to interbasin freshwater transport by the atmosphere and the Bering Strait throughflow. J. Climate, 15, 2516-2526.

$\mathrm{Hu}$, A., and G. D. Meehl, 2005: Bering Strait throughflow and the thermohaline circulation. Geophys. Res. Lett., 32, L24610, doi:10.1029/2005GL024424.

Hu, F. S., D. Slawinski, H. E. Wright Jr., E. Ito, R. G. Johnson, K. R. Kelts, R. F. McEwan, and A. Boedigheimer, 1999: Abrupt changes in North American climate during early Holocene times. Nature, 400, 437-440.

Labeyrie, L., 2000: Glacial climate instability. Science, 290, $1905-$ 1907.

Marotzke, J., 2000: Abrupt climate change and thermohaline circulation: Mechanisms and predictability. Proc. Natl. Acad. Sci. USA, 97 (4), 1347-1350.

Nof, D., 2000: Does the wind control the import and export of the South Atlantic? J. Phys. Oceanogr., 30, 2650-2667.

_ correspond to an invasion of Pacific water into the Atlantic? J. Phys. Oceanogr., 33, 1324-1336.

Rahmstorf, S., 2006: Thermohaline ocean circulation. Encyclopedia of Quaternary Sciences, S. A. Elias, Ed., Elsevier, 1-10.

Reason, C. J. C., and S. B. Power, 1994: The influence of the Bering Strait on the circulation in a coarse resolution global ocean model. Climate Dyn., 9, 363-369.

Sandal, C. K., 2006: A new dynamical explanation for the abrupt temperature rise in the beginning of the Holocene. Ph.D. dissertation, The Florida State University, $104 \mathrm{pp}$.

— , and D. Nof, 2008a: A new analytical model for Heinrich events and climate instability. J. Phys. Oceanogr., 38, 451466.

$\longrightarrow$, and $-2008 \mathrm{~b}$ : Laboratory experiments on the paleojamming of the Bering Strait. Deep-Sea Res., in press.

Shaffer, G., and J. Bendtsen, 1994: Role of the Bering Strait in controlling North Atlantic ocean circulation and climate. $\mathrm{Na}$ ture, 367, 354-357.

Stocker, T. F., 2002: North-south connections. Science, 297, 1814 1815.

Stouffer, R. J., and Coauthors, 2006: Investigating the causes of the response of the thermohaline circulation to past and future climate changes. J. Climate, 19, 1365-1387.

Toulany, B., and C. Garrett, 1984: Geostrophic control of fluctuating barotropic flow through straits. J. Phys. Oceanogr., 14, 649-655.

Wadley, M. R., and G. R. Bigg, 2002: Impact of flow through the Canadian Archipelago and Bering Strait on the North Atlantic and Arctic circulation: An ocean modelling study. Quart. J. Roy. Meteor. Soc., 128, 2187-2203.

Yokoyama, Y., K. Lambeck, P. De Deckker, P. Johnston, and L. K. Fifield, 2000: Timing of the Last Glacial Maximum from observed sea-level minima. Nature, 406, 713-716. 